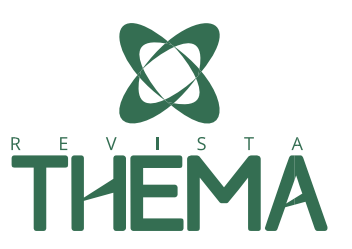

\title{
A produção do conhecimento a respeito da formação inicial de professores: desafios e expectativas
}

\section{The production of knowledge about initial teacher education: challenges and expectations}

\author{
Guilherme Salgueiro Goulart ${ }^{1}$; Charles dos Santos Guidotti²; Carla Beatriz Spohr ${ }^{1}$
}

\section{RESUMO}

Nesse estudo buscamos compreender o que está sendo comunicado, com base nos periódicos Ciência e Educação e Ensaio Pesquisa em Educação em Ciências, sobre formação inicial de professores. Utilizamos o Estado da Arte como forma de verificar o que está sendo discutido, com relação à temática, dentro do âmbito científico. Como metodologia de análise de dados, utilizou-se a Análise Textual Discursiva, chegando assim a quatro categorias, cujas quais, neste trabalho, exploramos apenas duas delas. Com base nos artigos estudados verificamos a necessidade de se problematizar a formação inicial de professores, uma vez que esta será uma das responsáveis pela constituição do futuro professor.

Palavras-chave: formação inicial de professores, desafios, educação.

\begin{abstract}
This research aims to investigate, understand and problematize teacher training process regarding the challenges will be facing during their practice. Thereby, articles published over the last ten years in the journals Ciência \& Educação and Ensaio Pesquisa em Educação em Ciências were taken as object of study in order to check what has been discussed in relation to this issue. In order to understand the object of research, we use the state of art as a way to verify what is being discussed, in relation to the subject, within the scientific scope. As a methodology of data analysis, the Discursive Textual Analysis thus reaching four categories, whinch, in this work, we explore only two of them. Based on the articles studied, we verified the need to problematize the initial teacher training, since this will be one reason for the formation of the future teacher.
\end{abstract}

Keywords: initial teacher training, challenges, education.

\section{INTRODUÇÃO}

O ser professor vai muito além de ter sido afagado com o privilégio da docência. Não nascemos professores, mas sim construímo-nos ao longo de nossa trajetória, por meio das diferentes experiências, vivências, percepções e interações constituídas (NOGUEIRA, 2003). Nesse sentido, diversos são os desafios experienciados durante a vida profissional docente, que perpassam, por

\footnotetext{
1 UNIPAMPA - Universidade Federal do Pampa, Uruguaiana/RS - Brasil.

2 FURG - Universidade Federal do Rio Grande - Rio Grande/RS - Brasil.
} 
vezes, as práticas de ensino, chegando a questões muito mais complexas e que fogem do contexto de sala de aula.

No campo dos desafios presentes na educação, de acordo com Martins (2005), podemos citar aqueles ditos de primeira ordem, que englobam as condições de trabalho para que o profissional consiga desenvolver aquilo que lhe é atribuído, assim como a finalidade do que se está ensinando. Além disso, são apresentados pelo autor, os desafios ditos de segunda ordem que compreendem os aspectos formativos do profissional docente.

A partir disso, levando-se em conta os desafios de primeira ordem temos um paradigma vigente em nosso contexto atual, em que, por vezes, o profissional da educação trabalha em situações adversas, dispondo de poucos recursos o que dificulta ainda mais sua prática pedagógica. Martins (2005) nos diz que, infelizmente, este processo é oriundo de uma crise de imagem e de função, ocorrendo, por conseguinte, uma desvalorização social da profissão e que, muito embora, no imaginário popular se tenha a real dimensão da importância deste profissional, é salientado pelo autor, que o mesmo já não goza mais do status que possuía há décadas.

Sendo assim, segundo Martins (2005) a:

crise de imagem e de função que reforça e é reforçada pela baixa remuneração, levando o professor a um aumento de sua jornada de trabalho, que, por sua vez, certamente diminui a qualidade de sua produção e atuação pedagógica: não há como preparar boas aulas, corrigir os trabalhos e investir em sua própria formação, pois não existe tempo hábil para isso, em função do acúmulo de trabalho. Junte-se a isso dois fatores de ordem material: a precariedade do espaço escolar (muitas vezes de uma estrutura física adequada para a concretização do fenômeno "ensino") e a falta de material pedagógico (livros, laboratórios, computadores, entre outros elementos imprescindíveis a um bom aprendizado). (p. 55)

Outro fator preocupante está na organização curricular da educação básica, onde, muitas vezes, os conteúdos conceituais ensinados, não dialogam com o cotidiano do aluno, dificultando ainda mais o processo de ensino e aprendizagem. Devemos lembrar que, este estudante que se encontra na educação básica irá, possivelmente, frequentar o ensino superior. Logo, as dificuldades oriundas de um ensino básico deficitário o acompanharão por todo seu processo formativo.

De acordo com Junior, Palladino e Borges (2011) um ensino de base ruim dificilmente irá sustentar uma boa formação no nível superior, fato este que irá refletir de forma direta em sua profissão.

Contudo, mesmo com as dificuldades implícitas temos no campo de formação inicial de professores a demarcação de um elo fundamental e, portanto, imprescindível para que bons profissionais possam integrar o mercado de trabalho, auxiliando assim na melhora das condições de ensino. Entretanto, a forma como será conduzida esta formação é um elemento fundamental aos professores em formação inicial. Infelizmente, a formação de professores tem sido balizada de forma a produzir profissionais que visem incorporar ideais que dialoguem a partir de uma proposição teórica, pautada, basicamente, na transmissão de conhecimentos específicos o que, por si só, acabam, muitas vezes, por tornar simplório e desinteressante os processos de ensino e aprendizagem. O pensamento decorrente desta prática leva a crer que o futuro professor estará capacitado a enfrentar uma sala de aula apenas portando os conhecimentos de conteúdos específicos de sua área de formação. 
Viveiro e Campos (2014) nos dizem que em muitos cursos de licenciatura há uma reduzida articulação entre as disciplinas de conteúdo específico, com predomínio de aulas expositivas e de laboratório, onde muitos docentes acreditam que para lecionar, basta que o aluno tenha bom aporte de conhecimentos específicos. Além disso, as autoras destacam que "Apesar das disciplinas pedagógicas explorarem práticas diversificadas, muitos licenciandos incorporam a visão acadêmica predominante no curso, repetindo o modelo dos professores que tiveram" (VIVEIRO e CAMPOS, 2014, p. 221). Torna-se, portanto um ciclo vicioso que interpela sujeitos na construção de uma educação voltada ao pragmatismo acadêmico.

Segundo Viveiro e Campos (2014, p. 223):

Estudos do final da década de 1980 já apontavam a necessidade de que os cursos de formação inicial de professores buscassem formas de articulação entre as disciplinas específicas, a formação educacional geral e as didáticas específicas. Além disso, destacavam a importância de novas formas de organização institucional que pudessem dar suporte a essas demandas bem como a urgência de pessoal preparado para formar os professores no Ensino Superior.

Com a promulgação das Diretrizes Curriculares Nacionais para a Formação de Professores e, posteriormente, com a aprovação das diretrizes específicas para cada curso, determinou-se, dentre outros aspectos, que "as licenciaturas tivessem maior carga horária de estágios supervisionados, ênfase em atividades teóricas e práticas relacionadas ao exercício da docência e que as práticas estivessem presentes desde o início do curso, permeando toda a formação"(VIVEIRO e CAMPOS, 2014, p. 224). Entretanto, mesmo com algumas mudanças conjunturais, nos cursos de licenciatura, que fomentam um exercício maior à docência, entra-se em um dilema, construído pelas próprias Universidades e Institutos Federais que preconizam a especificidade, uma vez que para ingressar como professor no ensino superior, de acordo com Oliveira e Silva (2012, p. 198) "a exigência é que se tenha o maior nível de formação específica na área de conhecimento em que vai atuar [...]".

A partir disso, Oliveira e Silva (2012, p. 198) nos dizem que:

O que podemos então perceber é que as Universidades e os Institutos Federais de Educação têm priorizado o domínio dos conhecimentos da área de formação dos bacharéis docentes bem como sua experiência profissional na área, proporcionando que, para tornar-se professor seja suficiente ter formação inicial, ser um bom profissional e ter uma sólida experiência na sua área de atuação. Nesse sentido, os conhecimentos específicos da docência que são de igual importância para a atuação como professores profissionalmente são menos considerados, ficando em segundo plano como citamos anteriormente, colocando apenas sob a responsabilidade do tempo e do exercício da profissão o possível aprendizado da mesma, como se isso fosse possível exclusivamente por meio da prática.

Com isso, muitas vezes, os docentes formadores de professores possuem título de bacharel o que nos conduz à percepção de que o título de licenciado é apenas uma diferenciação semântica entre as modalidades. Nesse sentido, concordamos com Oliveira e Silva (2012) que nos diz que o reconhecimento social da profissão docente é oriundo de uma grande luta desenvolvida ao longo de muitos anos, possuindo características que lhes são peculiares e que, portanto, não devem ser exercidas por pessoas sem a formação específica para tal atividade.

A partir disso, se vê o quão importante é este aspecto formativo; caráter fundamental para o desenvolvimento do licenciando quanto um futuro profissional da área da educação, uma vez que esta será o molde inicial de sua prática docente e que permitirá ao professor enfrentar os diversos 
desafios presentes na sala de aula. Logo, é importante que, durante a formação inicial, este licenciando disponha de informações que o levem a modelar sua prática docente, baseando-se na perspectiva de que nossa sociedade exige profissionais que levem os educandos à autonomia intelectual e à criticidade, fazendo-se com que se desenvolva uma sociedade mais justa e igualitária.

Dentro desta mesma perspectiva, Freitas e Villani (2002, p. 1) nos dizem que:

Tem-se como perspectiva a construção de novas estratégias para a formação de recursos humanos para a educação de forma a incorporar as mudanças dos sistemas produtivos que exigem um novo perfil profissional capaz de localizar os desafios mais urgentes de uma sociedade "multimídia e globalizada", em que o rápido desenvolvimento, científico e tecnológico, impõe uma dinâmica de permanente reconstrução de conhecimento, saberes, valores e atitudes. Se quisermos ser um pouco mais críticos, podemos também nos perguntar quais são as alienações fundamentais de tal sociedade que seria interessante enfrentar, a fim de que a formação de professores de ciências contribua para mudanças culturais e sociais possíveis e desejáveis.

A partir desses pressupostos, utiliza-se o estado da arte como linha de atuação dessa pesquisa, buscando assim, verificar o que está sendo discutindo no meio científico, com base na busca em dois periódicos, sobre a formação inicial de professores. Além disso, visamos compreender e problematizar qual a influência da formação inicial na vida docente.

\section{METODOLOGIA}

A metodologia deste trabalho divide-se em dois processos que serão detalhados a seguir.

\subsection{Caminhada Metodológica Inicial}

Para estruturar nossa pesquisa definimos como objeto de estudo as Revistas Ciência \& Educação (Bauru) e Ensaio Pesquisa em Educação em Ciências. Essa escolha se justifica na medida em que ambas têm como foco a divulgação de trabalhos desenvolvidos no campo da educação em ciências. Além disso, são periódicos brasileiros de referência no Ensino de Ciências, tendo em vista que, ambas possuem Qualis A1 e diversas publicações na área.

Após a escolha das revistas, partimos na busca por selecionar formas de estruturar os dados desta pesquisa. Com isso, pensaram-se, pelo contingente de informações, na elaboração de critérios para a selecionar os textos que seriam analisados.

O tempo escolhido para a análise dos periódicos, últimos 10 anos (2005 - 2015), foi em decorrência de uma entrevista concedida pelo então ministro da educação, no ano de 2005, que destaca esse como "O ano da Educação".

Segundo Brasil (2005, p. 1)

"[...] está sendo desenvolvido nesse ano mais de 250 programas de educação e formação, dando atenção ao ensino superior, promovendo intercâmbio de informações entre o Brasil e outros países e tem como meta começar a revolucionar o ensino básico do país a partir do ano que vem".

Com isso, esse ano demarca uma mudança conjuntural junto às universidades, onde se dá uma atenção especial ao Ensino Superior e a formação inicial de professores (BRASIL, 2005), preparando- 
se o campo para a implementação, em anos posteriores, de programas fundamentais, como por exemplo: Programa de Consolidação das Licenciaturas (2006), PIBID (2007) e PARFOR (2009), programas que auxiliariam no desenvolvimento de uma formação inicial mais integra e completa.

Delimitado o tempo para análise dos periódicos, voltamo-nos a coleta das informações junto aos periódicos, estado da arte, onde verificamos que as revistas analisadas possuem, em seu formato online, em cada um de seus números, um resumo contendo as palavras-chave daquele artigo e que sintetizam o texto que será apresentado aos leitores. Pensando nisso, optou-se por analisar os artigos que apresentassem as palavras formação inicial de professores, e também, similares, como licenciatura, formação básica, estágio supervisionado e graduação.

A partir disso, foram recuperados e analisados 130 artigos, dos quais 90 artigos decorrentes da Revista Ciência e Educação (Bauru) e 40 da Revista Ensaio Pesquisa em Educação e Ciências, todos esses artigos abordam o tema formação inicial de professores, uma vez que o objetivo dessa pesquisa é verificar o que está sendo discutido com relação à formação inicial de professores.

\subsection{Análise das Informações: Análise Textual Discursiva}

Por ser uma pesquisa qualitativa onde buscamos compreender um fenômeno e não obter resultados a priori, utilizamos a metodologia da análise textual discursiva (ATD) como forma de análise das informações obtidas, uma vez que, segundo Moraes e Galiazzi (2011, p.7) este consiste em "um modelo metodológico de análise de informações de natureza qualitativa com finalidade de produzir diferentes compreensões sobre os fenômenos e discursos investigados". Logo, pode-se ressignificar, reconstruir, interpretar e compreender melhor os textos estudados, ao passo que se atribui uma nova ótica, oriunda dos conhecimentos e pressupostos teóricos do pesquisador, ao objeto de estudo em questão.

Nesse sentido, Moraes (2007, p. 15) aponta que:

Toda Leitura é feita a partir de uma perspectiva teórica, seja esta consciente ou não. Ainda que se possa admitir o esforço pôr entre parênteses essas teorias, qualquer leitura implica ou exige algum tipo de teoria para poder concretizar-se. É impossível ver se teoria; é impossível ler e interpretar sem ela.

Com isso, o processo da ATD é estruturado a partir de três grandes movimentos: a desmontagem dos textos (também chamada de processo de unitarização), estabelecimento de relações (categorização) e captação de novos emergentes (MORAES, 2003).

A ATD inicia com a desconstrução dos textos, processo que consiste na criação de fragmentos unitários, unidades de significado, que estão de acordo com o objeto de estudo do pesquisador. A partir disso, Moraes (2003, p. 192) no diz que "ao examinar esse elemento, fazemos, em primeiro lugar, uma incursão sobre o significado da leitura e sobre os diversificados sentidos que esta permite construir a partir de um mesmo texto". Dentro desta mesma perspectiva Guidotti $(2014$, p. 75$)$ reitera que o processo de unitarização é o momento em que o pesquisador mergulha em seu corpus, na caça de unidades de significados.

A unitarização compreende ainda três momentos distintos, onde o pesquisador irá, em um primeiro momento, fragmentar e codificar cada uma das unidades de significado. Este processo de 
categorização é fundamental, ao passo que o pesquisador possa sempre retornar, quando necessário, ao texto de origem (GUIDOTTI, 2014). Em nossa pesquisa, em um primeiro momento, os artigos analisados foram dispostos em uma planilha do Excel, sendo então demarcadas por letra do alfabeto (A), representando a letra inicial da palavra artigo seguida pelo número do texto que deu origem à unidade.

Após esse processo inicial, realizou-se a leitura de cada um dos resumos contidos nos periódicos, desmembrando-os de forma a produzir unidades de significado para nossa pesquisa. Essas unidades de significado receberam códigos, por exemplo: U1- unidade 1.

\begin{tabular}{|c|c|}
\hline Código & Unidades de Significados \\
\hline A1 & $\begin{array}{l}\text { U1. Programas especiais de formação pedagógica e suas implicações na formação de professores de ciências. Em um } \\
\text { primeiro momento, buscamos a compreensão desses cursos nos documentos oficiais, contextualizando-os como uma } \\
\text { política pública para formação de professores. }\end{array}$ \\
\hline A2 & Não tem Unidades de significado \\
\hline A3 & $\begin{array}{l}\text { U2. A construção e acúmulo de conhecimentos pelo professor se dão ao longo de sua } \\
\text { vida, por meio de suas experiências pessoais, formativas e profissionais, e compreende a reflexão como } \\
\text { processo potencializador da aprendizagem profissional da docência }\end{array}$ \\
\hline A4 & $\begin{array}{l}\text { U3. Análise documental no conjunto de documentos das Diretrizes Curriculares } \\
\text { para os Cursos de Matemática }\end{array}$ \\
\hline A5 & U4. Importância do uso de textos paradidáticos na formação dos licenciandos em Física \\
\hline A6 & U5. Formação de professores de ciências no âmbito da educação inclusiva \\
\hline A8 & U6. Materiais didáticos elaborados por professores \\
\hline A9 & U7. Produção de narrativas na formação de alunos de Licenciatura em Ciências Biológicas \\
\hline A10 & $\begin{array}{l}\text { U8. Conhecimentos sobre o ensino de matemática que estão sendo explicitados nas pesquisas dos professores produzidas } \\
\text { nos âmbitos do Mestrado (Profissional e Acadêmico) e do Observatório da Educação, as quais se fundamentam na } \\
\text { perspectiva da Atividade Orientadora de Ensino }\end{array}$ \\
\hline
\end{tabular}

Figura 1: Recorte representando as unidades de significados e suas codificações.

Nesse sentido durante esta primeira etapa buscou-se desmembrar os periódicos em unidades de significados, que apresentassem ideias semelhantes e de acordo com o objetivo de nossa pesquisa, para então, mais a frente reconstruir novas unidades. Por exemplo, em A18, os autores trazem que: "A análise dos dados apontou que a profissão docente e o seu desenvolvimento profissional constituem elemento fundamental para assegurar a qualidade do processo ensino-aprendizagem" (URZETTA e CUNHA, 2013, p.841). Já A53 (RIBEIRO e BENITE, 2010, p.585) nos diz que:

"[...] Por essa razão, foram investigadas as percepções sobre educação inclusiva de todos os professores formadores de um curso de licenciatura em Química de uma Instituição de Ensino Superior (IES) pública de Goiás, já que são esses que preparam os futuros professores e suas opiniões têm influência no currículo do curso

Logo, as unidades de significado de cada artigo demonstram similaridades com relação a formação inicial de professores. Com isso, podem ser agrupadas dentro de uma mesma "categoria", gerando assim uma nova unidade.

Na segunda etapa da ATD, a partir das informações emergentes dos artigos analisados, buscou-se estabelecer relações entre os elementos das unidades de significado. Para isso, relacionaram-se as unidades a partir de tópicos que apresentasse ideias em comum, esta é a chamada etapa de categorização. 
Segundo Moraes (2007, p. 75):

(...) a categorização revela-se um exercício de classificação dos materiais de um "corpus" textual. Nisso um conjunto desorganizado de elementos unitários é ordenado no sentido de expressar novas compreensões atingidas no decorrer da pesquisa. Esse processo de classificação é recursivo e interativo, avançando no sentido de, gradativamente, se explicitarem com maior clareza e precisão as categorias dos fenômenos, assim como as próprias regras de categorização.

Através deste movimento de categorização serão fornecidos elementos propícios para que sejam gerados os metatextos, ou seja, novas significações decorrentes da desconstrução dos artigos (PINHO, 2014).

A partir desse movimento de categorização, chegamos a doze subcategorias que decorrem da desconstrução e reconstrução dos resumos analisados em cada periódico.
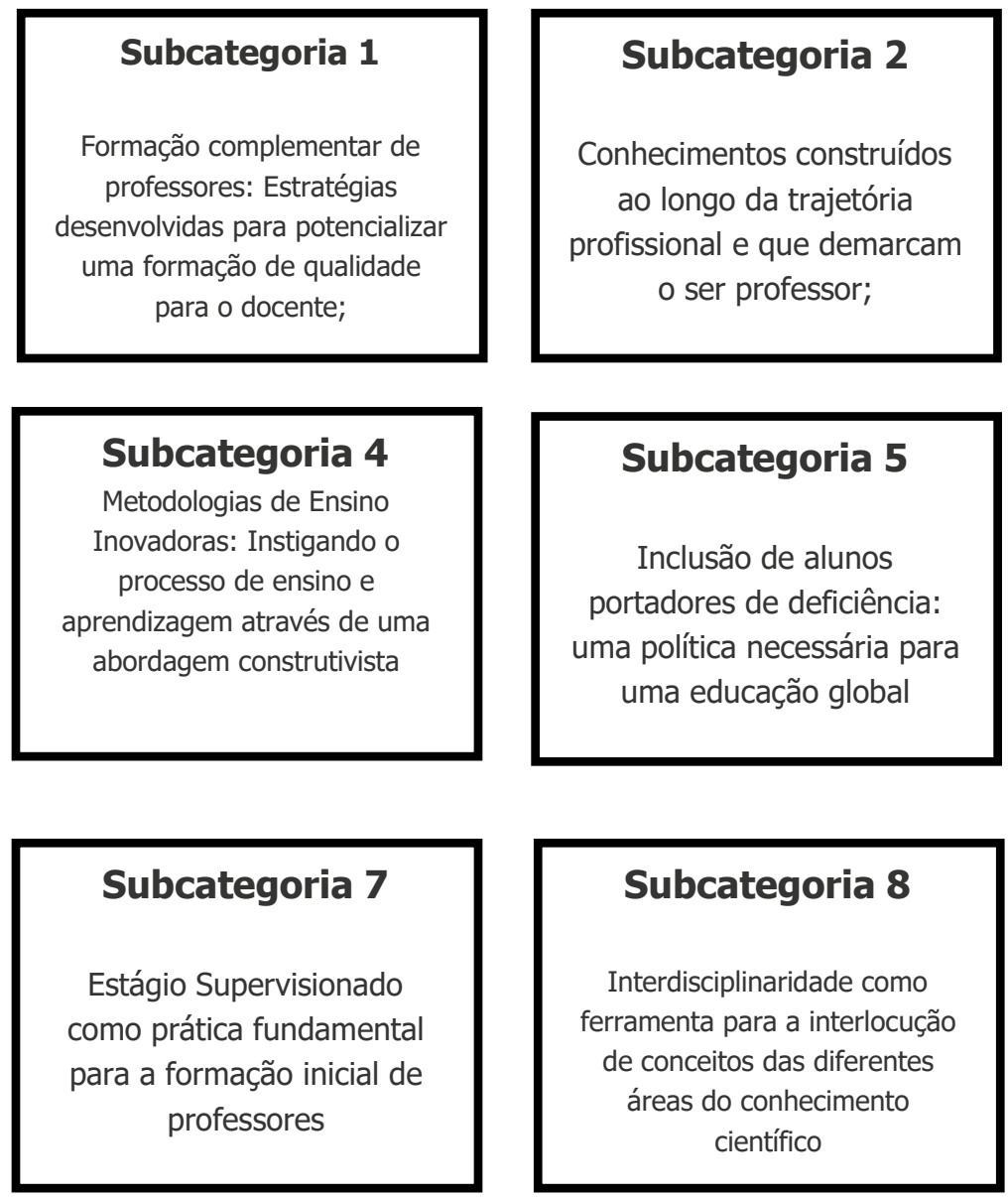

\section{Subcategoria 10}

A importância da utilização das TICs na formação inicial de professores como forma de (re) significação econtextualização do processo de ensino e aprendizaqem

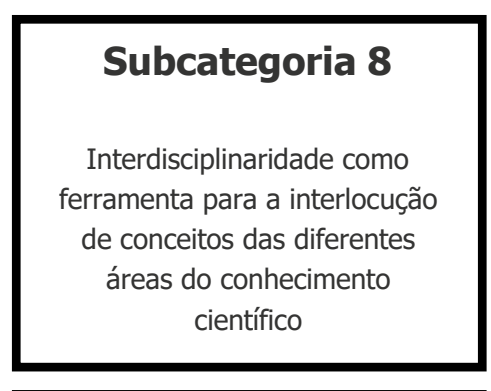

\section{Subcategoria 11}

Incentivando à pesquisa na formação inicial: formando professores pesquisadores que reflitam sobre sua prática docente

\section{Subcategoria 3}

Documentos norteadores da formação inicial de professores como estruturantes de um processo formativo

\section{Subcategoria 6}

Professores de Licenciatura como estimuladores das práticas pedagógicas dos docentes em formação

\section{Subcategoria 9}

Formação docente deficitária e a necessidade readequação no currículo da Universidade: Uma forma de

aproximação entre as realidades

\section{Subcategoria 12}

Pós-graduação: Especialização, Mestrado e Doutorado, contribuindo significativamente para a qualificação docente

Figura 2: Subcategorias 
Com o desenvolvimento das subcategorias, surgem novas compreensões sobre o fenômeno investigado, uma vez que durante o movimento de síntese e organização, as subcategorias são unidas a partir de suas semelhanças, acontecendo, assim, "um novo processo de reintegração e reagrupamento de ideias, articulando a evidencias empíricas e teóricas" (GUIDOTTI, 2014, p.76).

Nesse sentido Pinho (2014, p. 31) complementa nos dizendo que:

É importante citar que os metatextos não devem ser apenas interpretações do que se percebe ancoradas nas ideias de quem realiza a análise. As teorias e perspectivas emergentes devem ser sempre consideradas e preservadas, tal como os contextos em que se encontram os autores e os relatos escolares. Sendo assim, a reconstrução é autoria do pesquisador e deve se ancorar em seus aportes teóricos, porém sem desconsiderar o que já foi dito antes.

Dessa forma chegamos a quatro categorias finais:

\section{Categoria 1}

Os desafios docentes frente a uma educação contemporânea:

$(\mathrm{Re})$ significando metodologias de ensino a partir do uso das TICs junto a educandos portadores de deficiência.

\section{Categoria 3}

$\mathrm{O}$ que dizem as Diretrizes Curriculares para a Formação Inicial e Continuada dos Profissionais do Magistério da Educação Básica sobre a importância do estágio supervisionado, assim como também, sua importância na construção de conhecimentos para seu futuro como docente;

\section{Categoria 2}

Problematizando os formadores e docentes em formação inicial com base

na grade curricular dos cursos de licenciatura: Novas perspectivas a partir de uma educação Interdisciplinar e que estimule o ensino com base na pesquisa.

\section{Categoria 4}

A busca por uma educação de qualidade: Qualificação docente a partir de uma formação complementar para professores com licenciatura curta e/ou o ingresso em uma pós-graduação lato senso ou stricto sensu.

Figura 3: Categorias

A partir das quatro categorias emergentes iniciamos a estruturação de um processo de descrição e interpretação, onde iremos fornecer novas compreensões emergentes da análise desenvolvida. Nesse sentido, de acordo com Hecker, et al (2013, p. 9) "O processo de compreender o que acontece ao operar o objeto aperfeiçoável desafia os pesquisadores à imersão no diálogo investigativo, na ressignificação das questões e compreensões atribuídas as questões iniciais que norteiam à temática". Sendo assim, durante todo este processo iremos escrever, ler e dialogar com diversos interlocutores, procurando ressignificar e reconstruir as unidades de significado (GUIDOTTI, 2014).

As categorias serão discutidas e problematizadas a partir dos quatro metatextos construídos a partir da ATD, sendo estes: 1) Os desafios docentes frente a uma educação contemporânea: (Re)significando metodologias de ensino a partir do uso das TICs junto a educandos portadores de deficiência; 2) Problematizando os formadores e docentes em formação inicial com base no currículo dos cursos de licenciatura: Novas perspectivas a partir de 
uma educação Interdisciplinar e que estimule o ensino com base na pesquisa; 3) 0 que dizem as Diretrizes Curriculares para a Formação Inicial e Continuada dos Profissionais do Magistério da Educação Básica sobre a importância do estágio supervisionado, assim como também, sua importância na construção de conhecimentos para seu futuro como docente; 4) A busca por uma educação de qualidade: Qualificação docente a partir de uma formação complementar para professores com licenciatura curta e/ ou o ingresso em uma pós-graduação lato senso ou stricto sensu.

Cabe-se ressaltar ainda que, neste artigo, iremos explorar apenas os metatextos 2 e 3. Justamente por entendermos que ambos estão relacionados e vem a se complementar, uma vez que é no Estágio Supervisionado que o licenciando irá ter sua primeira experiência profissional, aplicando assim, todos os conhecimentos teóricos aprendidos durante a sua graduação. Entretanto, os demais metatextos serão enfatizados em trabalhos futuros, uma vez que possuem alta relevância quando tratamos de formação inicial.

\section{PROBLEMATIZANDO OS FORMADORES E DOCENTES EM FORMAÇÃO INICIAL COM BASE NO CURRÍCULO DOS CURSOS DE LICENCIATURA: NOVAS PERSPECTIVAS A PARTIR DE UMA EDUCAÇÃO INTERDISCIPLINAR E QUE ESTIMULE O ENSINO COM BASE NA PESQUISA.}

Não é de hoje que se discute a formação de professores dentro do cenário brasileiro. Entretanto, nos últimos 30 anos, debates como este se encontram cada vez mais recorrentes em discussões acadêmicas, tendo, essas investigações sobre a profissão docente nas universidades e instituições de pesquisa no Brasil, se acentuado, principalmente a partir de 1990, o que nos leva a evidenciar o quão inquietante tem sido esta problemática ao longo dos últimos anos (PEREIRA, 1999).

Talvez, a grande gama de conhecimentos produzidos na área se de por conta de um dos problemas levantados por Pereira (1999) que consiste na estagnação do modelo de estrutura das licenciaturas, onde, segundo o autor, este permanece, desde sua origem na década de 1930, sem possuir alterações significativas. Portanto, sem a proposição de mudanças, temos a instauração de alguns problemas nos cursos de licenciatura como a separação entre as componentes curriculares específicas e as pedagógicas, ou ainda a articulação que se faz necessária entre a formação acadêmica e a realidade profissional deste futuro professor.

Em nossa pesquisa, a partir de um total de cento e trinta artigos (Anexo) analisados, verificou-se que quinze destes apontam para a necessidade de uma reestruturação curricular nos cursos de licenciatura. A maioria destes dá ênfase à necessidade de o professor integrar os conhecimentos específicos juntamente aos pedagógicos, assim como também é destacado que esta reestruturação deve incorporar conhecimentos significativos e que serão, efetivamente, trabalhados na educação básica. Essa concepção é verificada a partir do artigo A50 (ROSA e PAVAN, 2011) que nos diz que:

As licenciaturas se apresentam como cursos híbridos em que parte dos conteúdos específicos não se articula com as disciplinas de cunho pedagógico, e estas se apresentam com um mínimo de disciplinas no cômputo geral do curso. (p. 93)

Com relação à importância do conhecimento específico e pedagógico, sabe-se que ambos são fundamentais dentro do contexto de formação inicial de professores. Desde o início da criação das 
licenciaturas nas escolas de filosofia no Brasil, nos anos 30, já se trabalhava com a perspectiva de relacionar a teoria com a prática profissional. De acordo com Pereira (1999, p. 111) esta se constituiu a partir da "fórmula " $3+1$ ", em que as disciplinas de natureza pedagógica, cuja duração prevista era de um ano, justapunham-se às disciplinas de conteúdo, com duração de três anos". Este modelo, a partir de uma busca na literatura educacional, pode ser analogamente, associado com o modelo da racionalidade técnica, onde o professor é visto como um técnico que aplica com rigor os conhecimentos teóricos aprendidos em sua prática docente (PEREIRA, 1999).

Em várias Universidades brasileiras o modelo da racionalidade técnica ainda é frequentemente utilizado. Entretanto é inegável que este modelo traz consigo uma série de agravantes preocupantes se levarmos para o contexto da formação de professores. Pereira (1999) cita como principais críticas ao modelo o fato de este provocar uma segregação entre os conhecimentos teóricos e práticos, além de fomentar a ideia de que para ser um bom professor é necessário que se tenha apenas o domínio da área do conhecimento que se está ensinando. Portanto, dentro deste paradigma é diminuída a importância da prática profissional.

Em nossa pesquisa essa questão é discutida no artigo A37 (QUADROS, p. 310, 2012) que nos diz que:

Apesar da incontestável titulação acadêmica, são comuns relatos de estudantes sobre professores que dominam o conteúdo, mas têm dificuldades de ensiná-lo e/ou transmiti-lo e, assim, não conseguem conduzir uma aula, atuando, algumas vezes, de forma arrogante e, ainda, mostrando-se mais interessados em seus trabalhos de pesquisa, em detrimento da atividade docente.

Em outro viés, o artigo A40 (ALMEIDA e LIMA, 2012) retoma a ideia de aglutinar os conhecimentos específicos e pedagógicos, trabalhando-os de forma igualitária. No artigo traz-se como exemplo um curso de licenciatura em pedagogia, onde se problematiza essa questão, sendo salientado pelos autores, que "é fundamental que as disciplinas procurem promover uma integração entre os saberes disciplinares de matemática e os saberes pedagógicos necessários ao trabalho com esses conteúdos nas séries iniciais do Ensino Fundamental" (ALMEIDA e LIMA, p. 464, 2012).

Essa ruptura entre os conhecimentos de cunho específico e pedagógico é também discutida por Libâneo (2010, p. 566) que salienta que:

A presença, nos currículos, de disciplinas de "fundamentos" e disciplinas voltadas ao exercício profissional do professor, leva a supor que as primeiras teriam a função de prover ao futuro professor os elementos teóricos da profissão, e as segundas de formação para as demandas da prática docente na escola e na sala de aula. No entanto, um ligeiro olhar sobre as ementas permite concluir que é muito tênue a relação das disciplinas de "fundamentos" com as práticas, enquanto que as disciplinas referentes à formação profissional, em boa parte, não recorrem aos "fundamentos" e, frequentemente, dão a impressão de que "ficam na teoria", desdenhando o "quê" e o "como" ensinar

A falta de interlocução entre estes conhecimentos faz com que, muitas vezes o licenciando saia da universidade sem a devida preparação para atuar na educação básica, uma vez que a estrutura curricular dos cursos de formação de professores está pautada no desenvolvimento de conteúdos específicos que, na maioria das vezes, não dialogam com realidade vista durante a prática pedagógica deste professor (LIBÂNEO, 2010). 
Outra questão levantada durante a análise dos dados obtidos é de que esta reestruturação curricular não compreende apenas a interlocução entre os saberes específicos e pedagógicos. No artigo A27 (SANGIOGO, 2013), por exemplo, é levantada pelo autor, outra problemática referente à reestruturação curricular, onde é discutido que esta é um processo fundamental e necessário que pode contribuir para a superação da transmissão de conceitos, tornando os conteúdos mais significativos aos alunos. Logo, a reestruturação curricular dos cursos de licenciatura deveria embarcar facetas que contribuíssem para que o licenciando conseguisse verificar métodos de como trabalhar com seus alunos, de forma significativa, determinados conceitos aprendidos em sua graduação.

Além disso, Moreira e Silva (1995) amplia a ideia de currículo, dizendo que ao currículo não deve ser atribuído apenas o significado de sistematizar conhecimentos, mas sim que este possui um papel político, onde são estabelecidas relações que irão caracterizar o profissional em formação.

A Teoria Curricular não pode mais, se preocupar apenas com a organização do conhecimento escolar, nem pode encarar de modo ingênuo e não-problemático o conhecimento recebido. O currículo existente, isto é, o conhecimento organizado para ser transmitido nas instituições educacionais, passa a ser visto não apenas como implicado na produção de relações assimétricas de poder no interior da escola e da sociedade, mas também como histórica e socialmente contingente (MOREIRA, 1995, p. 21).

A partir disso, Moreira e Silva (1995, p. 11) convida-nos a refletir através de uma série de indagações:

Estarão os cursos de Licenciatura contribuindo para fortalecer o poder de seus estudantes? Em que medidas as estratégias e as relações que se desenvolvem na universidade têm favorecido esse fortalecimento? Esses questionamentos são bem recebidos quando se coloca em discussão o comprometimento desses cursos na formação de sujeitos autônomos, críticos, criativos e comprometidos como a democracia e a justiça social.

Logo, vemos que o perfil profissional docente começa durante sua formação inicial. Nesse sentido está implícita a importância do Currículo para o estudante, uma vez que este constitui também a sua identidade.

Dentro desta mesma perspectiva Silva (2002, p.15) nos diz que:

Quando pensamos em Currículo pensamos apenas em conhecimento, esquecendonos de que o conhecimento que constitui o Currículo está inextricavelmente, centralmente, vitalmente, envolvido naquilo que somos, naquilo que nos tornamos: na nossa identidade, na nossa subjetividade.

Outro agravante está no fato de que, muitas vezes os docentes formadores de professores possuem o grau de bacharéis, ou seja, estão aptos a formar sujeitos sem ter cursado disciplinas de cunho pedagógico, fazendo com que, muitas vezes, este professor possua um grande conhecimento dentro da área específica ao qual possui sua graduação, entretanto, tenha lacunas em sua didática, o que irá, com certeza, dificultar o processo de ensino e aprendizagem de seus alunos.

Assim, o bacharel torna-se professor sem nenhum tipo de formação pedagógica e os licenciados por sua vez assumem a profissão com lacunas em seu processo formativo. Este fenômeno não é um problema que se limita aos Institutos Federais de Educação, Ciência e Tecnologia, nem apenas as Universidades Federais, pois o problema tem início na própria legislação que precisa ser mais enfática na necessidade dos conhecimentos didático-pedagógicos dos docentes que passam a compor os quadros funcionais dessas instituições, pois até o momento fica a critério e responsabilidade 
institucional proporcionar ou não cursos de formação continuada de curta duração aos ingressos no cargo de professor. (OLIVEIRA e SILVA, 2012, p. 196).

A partir de nossa pesquisa é possível mapearmos essa problemática com base no artigo A129 (Quadros et al, 2005, p.6), relata que:

A peculiaridade da formação do professor, por ter em seu mundo de trabalho o mesmo "espaço" no qual foi formado, ou seja, a sala de aula, favorece a que ele assuma, depois de formado, não só a posição física de seus professores, mas também a postura, atitudes, formas de ensinar etc, fazendo um efeito "espelho"

Com isso, se temos por base uma formação inicial que preconize a transmissão de conceitos, teremos, possivelmente, professores que irão trabalhar dentro destes mesmos moldes.

Nesse sentido, é destacada também por Oliveira e Silva (2012), a importância de que a formação pedagógica do professor universitário seja encarada como um pré-requisito para o exercício da docência, fazendo com que se revejam as formas de admissão de novos professores nas Universidades.

No que tange os professores que já atuam no Ensino Superior, principalmente em cursos de formação de professores, Câmara (2010, p.11) destaca que:

[...] diferente do professor formado nas licenciaturas, o bacharel deve providenciar e investir na sua formação para a docência, corroborando com o pensamento que o professor tem a constituição de sua identidade docente pautada em princípios que valorem sua formação inicial.

Logo, é necessário que este profissional tenha a ciência da importância da parte pedagógica em sua vida profissional e então, busque formas e alternativas de investir em sua formação afim de que possa complementá-la. Entretanto, é importante destacar que, felizmente, no Brasil este cenário já está sendo revertido, uma vez que, de acordo com Masetto (2003, p.13):

Só recentemente os professores universitários começaram a se conscientizar de que seu papel no Ensino Superior, como o exercício de qualquer profissão, exige capacitação própria e específica que não se restringe a ter um diploma de bacharel, ou mesmo de mestre ou doutor, ou ainda apenas o exercício da profissão. Exige isso tudo, e competência pedagógica, pois ele é um educador.

É evidenciada também, a partir de nossa pesquisa, a proposição de um ensino com base na interdisciplinaridade. Durante a análise dos dados, foi possível verificarmos que oito, dos cento e trinta artigos discutiam a importância da interdisciplinaridade no currículo escolar. Essa ênfase dada à temática, dentro da formação inicial de professores, mostra-se preponderante e fundamental de ser discutida, uma vez que uma abordagem interdisciplinar possibilita que o aluno vivencie que os conhecimentos estudados por ele não estão estruturados de forma fragmentada, mas sim, a partir de um elo de complementaridade entre eles.

Segundo Thiesen (2008, p. 547):

O que se pode afirmar no campo conceitual é que a interdisciplinaridade será sempre uma reação alternativa à abordagem disciplinar normalizadora (seja no ensino ou na pesquisa) dos diversos objetos de estudo. Independente da definição que cada autor assuma, a interdisciplinaridade está sempre situada no campo onde se pensa a possibilidade de superar a fragmentação das ciências e dos conhecimentos produzidos por elas e onde simultaneamente se exprime a resistência sobre um saber parcelado. 
O artigo A90 (WEIGERT, VILLANI e FREITAS, 2005) nos traz outra perspectiva importante e que deve ser levada em consideração quando nos reportamos à interdisciplinaridade. Os autores nos lembram que os PCNs trazem uma ideia de interdisciplinaridade, ressaltando que a incorporação desta, implicaria em mudanças significativas dentro do currículo da educação básica, uma vez que, ocorreria a "[...] reorganização curricular em áreas de conhecimento, com o objetivo de facilitar o desenvolvimento dos conteúdos, numa perspectiva de interdisciplinaridade e contextualização" (BRASIL, 1999, p.7).

Esse fato nos leva a refletir sobre a implicação que esta mudança suscitaria, uma vez que muitos cursos de licenciatura ainda estão estruturados sobre uma óptica disciplinar. O artigo A52 (MIARKA e BICUDO, 2010) nos traz como exemplo a organização curricular de alguns cursos de matemática no Brasil:

No Brasil, a formação do professor de Matemática ocorre no Ensino Superior, no grau que se denomina graduação, geralmente com duração de oito semestres após o Ensino Médio, cujos currículos versam sobre: Matemática, com foco nas disciplinas de Álgebra, Geometria e Análise, e Educação, como Psicologia da Aprendizagem, Estrutura do Sistema Escolar, Prática de Ensino de Matemática e algumas disciplinas de caráter mais voltado à aplicação. (MIARKA e BICUDO, 2010, p.558)

Com isso nota-se outra dificuldade. Como estes professores irão trabalhar em uma perspectiva interdisciplinar a partir de uma formação inicial disciplinar?

Pietrocola, Pinho e Pinheiro (2003, p. 136) nos dizem que:

Balancear a formação disciplinar dos docentes não implica necessariamente em explodir a estrutura curricular disciplinar. Muitas vezes, ações pedagógicas pontuais podem diminuir o apelo disciplinar do pensamento dos futuros professores.

Logo, é defendido pelos autores que o professor em formação inicial tenha um espaço dentro de seu currículo de formação que o oportunize a discutir, preparar, aplicar a avaliar atividades de cunho interdisciplinar.

Além disso, é citada em nossa pesquisa a importância da formação de professores pesquisadores. Nesse sentido, temos no artigo A45 (SANGIOGO et al, 2011) a seguinte explanação:

Tal formação pode permitir, aos profissionais de ensino, nova visão do processo de ensino e aprendizagem em química, visão que, infelizmente, é fortemente baseada na concepção própria da racionalidade técnica em praticamente todos os cursos universitários (SANGIOGO et al, 2011, p.525)

Nesse mesmo sentido Maldaner (2003, p. 30) também ressalta que a formação de professores pesquisadores possibilita:

[...] refletir a respeito de sua prática de forma crítica, de ver a sua realidade de sala de aula para além do conhecimento na ação e de responder, reflexivamente, aos problemas do dia-a-dia nas aulas. É o professor que explica as suas teorias tácitas, reflete sobre elas e permite que os alunos expressem o seu próprio pensamento e estabeleçam um diálogo reflexivo recíproco que, dessa forma, o conhecimento e a cultura possam ser criados e recriados juntos a cada indivíduo. 
Essa questão mostra-se fundamental ao profissional de educação, uma vez que se constitui uma visão mais reflexiva, passível de uma autocrítica, a partir do momento em que se delega a opção de refletir sobre sua própria prática docente.

Em concordância a isso, o artigo A34 (OLIVEIRA e GONZAGA, 2012, p. 692) dialoga dizendo que:

De modo geral, considerando as diferenças de enfoques entre as abordagens teórico metodológicas, o movimento de formação do professor pesquisador configura-se na expressão do reconhecimento da importância da pesquisa na formação e no trabalho docente, considerando o papel ativo e crítico do professor como o sujeito investigador. Esse movimento de caráter político, social e epistemológico pode representar uma das estratégias de ressignificação do trabalho do professor, ou seja, a partir de uma formação específica, esse professor investigaria e produziria explicações sobre o ensino e a realidade educativa entendida como prática social.

Com isso, verifica-se a importância de a formação inicial contemplar elementos que preconizem um ensino com base na pesquisa, assim como também fornecer ao licenciando, instrumentos para que este consiga estabelecer relações entre os diversos conhecimentos construídos ao longo de sua graduação. Entretanto, para isso, se faz necessário que os professores universitários estimulem, durante sua prática pedagógica, metodologias que instiguem o estudante na busca por estes elementos.

\section{O QUE DIZEM AS DIRETRIZES CURRICULARES PARA A FORMAÇÃO INICIAL E CONTINUADA DOS PROFISSIONAIS DO MAGISTÉRIO DA EDUCAÇÃO BÁSICA SOBRE A IMPORTÂNCIA DO ESTÁGIO SUPERVISIONADO, ASSIM COMO TAMBÉM, SUA IMPORTÂNCIA NA CONSTRUÇÃO DE CONHECIMENTOS PARA SEU FUTURO COMO DOCENTE;}

O período do estágio supervisionado é um dos momentos mais importantes da formação inicial do professor. Esta etapa é composta por diversas incertezas, certa ansiedade, assim como, um período de autoafirmação profissional. De acordo com Bernardy e Paz (2012, p. 2): "O Estágio supervisionado é uma exigência da LDB - Lei de Diretrizes e Bases da Educação Nacional no 9394/96 nos cursos de formação de docentes". É no Estágio Supervisionado que o futuro professor se depara com a realidade que irá enfrentar assim que concluir sua formação inicial.

Entretanto, as formas como são conduzidas as aulas de estágio supervisionado tem sido propósito de grande discussão. Pimenta e Lima (2012, p. 33) interpelam seus discursos a partir da seguinte situação:

O estágio sempre foi identificado como a parte prática dos cursos de formação de profissionais, em contraposição à teoria. Não é raro ouvir, a respeito dos alunos que concluem seus cursos, referências como "teóricos", que a profissão se aprende "na prática", que certos professores e disciplinas são por demais "teóricos". Que "na prática a teoria é outra". (PIMENTA e LIMA, 2012, p. 33).

Em complementaridade ao fato exposto, Souza, Lucena e Segabinaz (2014) trazem a ideia do quão difícil é ministrar aulas de Estágio, nas licenciaturas, entretanto, é reconhecida pelos autores que estas são fundamentais, e que esta componente é a "espinha dorsal" dos cursos de licenciatura, pois oportuniza que o licenciando demonstre, na prática aquilo que lhe foi ensinado de forma teórica. 
Durante a análise das produções, observou-se que vinte trabalhos têm como tema central o estágio supervisionado, destacando esse como peça fundamental para uma boa formação de professores. Em concordância a esta afirmativa, trazemos, por exemplo, o artigo A33 (ROSA, WEIGERT e SOUZA, 2012, p. 678) que elucida a importância desta componente curricular dizendo-nos que:

O aluno de graduação, durante o estágio, vivência experiências, conhece melhor sua área de atuação e tem a oportunidade de aplicar os conhecimentos teóricos adquiridos. O estágio surge, então, como um processo fundamental na formação do aluno estagiário, pois é a forma de fazer a transição de aluno para professor.

Além disso, o artigo A113 (OLIVEIRA, 2009) nos lembra de que o Estágio Curricular Supervisionado é orientado a partir das Diretrizes Curriculares para a Formação inicial e Continuada de Profissionais do Magistério da Educação Básica, sendo componente fundamental da matriz curricular das licenciaturas, obedecendo a uma carga horária total de 400 horas.

A questão da carga horária total, alterada a partir do parecer CNE/CP 28/2001, na qual são acrescidas 100 horas às 300 horas de estágio já estabelecidas, elucida bem a importância do estágio curricular na formação docente, levando-nos e compreender que um bom profissional é formado não somente a partir de uma sólida formação técnica, mais sim a partir de suas vivências no bojo de sua profissão.

Ao se considerar o conjunto deste Parecer em articulação com o novo paradigma das diretrizes, com as exigências legais e com o padrão de qualidade que deve existir nos cursos de licenciaturas, ao mínimo legal de 300 horas deve-se acrescer mais 100 horas que, além de ampliar o leque de possibilidades, aumente o tempo disponível para cada forma de prática escolhida no projeto pedagógico do curso. Às trezentas horas são apenas o mínimo abaixo do qual não se consegue dar conta das exigências de qualidade. Assim torna-se procedente acrescentar ao tempo mínimo já estabelecido em lei (300 horas) mais um terço (1/3) desta carga, perfazendo um total de 400 horas. (BRASIL, 2001, p.10)

Outra questão suscitada a partir dos dados obtidos em nossa pesquisa é de que além do estágio possibilitar que o aluno interaja com a parte prática da profissão que irá exercer, este possibilita que o aluno perceba no professor que já atua em sala de aula, um parceiro que irá auxiliá-lo durante esta etapa de sua formação. Nesse sentido o artigo A102 (FEITOSA e LEITE, 2012, p. 46) discorre que:

Nos centros de formação de professores, o momento o qual é tradicionalmente marcante nesse sentido é o estágio supervisionado. Defendemos que nele existe uma interação entre os professores aprendizes-mestres (os estagiários) e os professores mestres mais experientes (professores colaboradores nas escolas, que recebem os licenciandos durante o período de estágio)

Além disso, o artigo A102 (FEITOSA e LEITE, 2012) nos traz outra perspectiva, na qual o estágio supervisionado não deve acontecer apenas no final do curso, mas sim permear toda a formação inicial docente, funcionando assim como um parâmetro de reflexão do futuro docente quanto suas perspectivas profissionais.

\section{CONSIDERAÇÕES FINAIS}

O presente artigo se propôs a refletir, compreender e problematizar a formação inicial de professores a partir de uma pesquisa documental, onde buscamos mapear o que se está discutindo, dentro do campo científico, com relação ao tema da pesquisa. Nota-se, a partir disso que a formação inicial docente tem sido amplamente discutida, tendo em vista que, mesmo com um curto espaço 
determinado para análise de nosso objeto de estudo, verificamos, nas duas revistas determinadas, um total de cento e trinta artigos que trazem em seu bojo a formação inicial docente.

Com a utilização da metodologia da Análise Textual Discursiva conseguimos compreender melhor nosso objeto de estudo, analisando-o a partir da ótica proposta no objetivo de nossa pesquisa, verificando assim que, embora muito se tenha feito para que seja melhorado o processo de formação inicial, ainda necessitamos romper com ideias fortemente arraigadas dentro das licenciaturas, como por exemplo, relacionar conhecimentos específicos com os pedagógicos.

É necessário destacarmos ainda uma discussão pertinente decorrente de um dos metatextos (Categoria 4) que encontrados durante o processo de ATD. O mesmo refere-se à formação complementar, através de cursos rápidos de complementação pedagógica, bem como também o aprofundamento na formação acadêmica através da pós-graduação lato senso/stricto sensu. Essa discussão é fundamental e reporta a uma possibilidade preocupante de que profissionais com notório saber atuem partir de cursos sem a complementação pedagógica, o que, ao nosso ver, seria um grande retrocesso no cenário educacional. Discussões como essa serão aprofundadas em um posterior trabalho, entretanto achamos pertinente citá-las neste artigo, justamente para auxiliar o leitor a refletir sobre essa questão.

Com isso, embora muitas sejam as dificuldades enfrentadas pelos licenciandos, muito por conta de as licenciaturas serem, historicamente, colocadas em um patamar inferior aos bacharelados, à perspectiva evidenciada a partir de nossa pesquisa é otimista, pois nota-se certa preocupação em reverter às defasagens do ensino brasileiro, com base naquele que é um dos principais atores no processo de ensino e aprendizagem: o professor.

\section{REFERÊNCIAS BIBLIOGRÁFICAS}

ALMEIDA, M. B.; LIMA, M. G. Formação Inicial de Professores e o Curso de Pedagogia: Reflexões sobre a Formação Matemática. Ciência \& Educação, Bauru, v. 18, n. 2, p. 451-468, 2012.

BERNARDY, K.; PAZ, D. M. T.; Importância do Estágio Supervisionado para a formação de professores, XVII Seminário Interinstitucional de Ensino, Pesquisa e Extensão, XV Mostra de Iniciação Científica, X Mostra de Extensão, UNICRUZ, 2012.

BRASIL. Ministério da Educação. Parecer CNE/CP n. 28, de 2 de outubro de 2001. Brasília, DF, 2001c. Disponível em: . Acesso em: 23 Mar. 2016.

BRASIL. 2005 será o início da revolução no ensino, p. 3, 2005. Disponível em: http://portal.mec.gov.br/arquivos/pdf/2004.8.9.14.10.30.pdf> Acesso em: 03 de Mar. de 2016.

BRASIL. Secretaria da Educação Média e Tecnológica. Parâmetros Curriculares para o Ensino Médio. Brasília: MEC, 1999.

CÂMARA, C. A. O. Docência no Ensino Superior: um desafio para a formação?. Revista Científica Eletrônica de Ciências Sociais Aplicadas da Eduvale, n. 05, p. 01-20, 2010.

FEITOSA, R. A.; LEITE, R. C. M. A formação de professores de ciências baseada em uma associação de companheiros de ofício. Revista Ensaio, Belo Horizonte, v. 14, n. 01, p. 35-50, 2012. 
FREITAS, D.; VILLANI, A. Formação de professores de ciências: um desafio sem limites. Investigações em Ensino de Ciências, Porto Alegre, v. 7, n. 3, 2002. Disponível em: <http://www.if.ufrgs.br/public /ensino/revista.htm> Acesso em: 16 de Jan. 2016.

GUIDOTTI, C. S. Investigando a Inserção das Tecnologias na Formação Inicial dos Professores de Física nas Universidades Federais do Rio Grande do Sul. Dissertação (Mestrado em Educação em Ciências: Química da Vida e Saúde) - Universidade Federal do Rio Grande, Rio Grande do Sul, 2014.

HECKLER, V. et al. O desenvolver metodológico na pesquisa -formação de professores da experimentação em ciências online. In: Anais do X Congresso Brasileiro de Ensino Superior a Distância. Belém, p. 1-14, 2013.

JUNIOR, C., A.; PALLADINO, A., A.; BORGES, S., E. A educação no Brasil, o ensino de ciências e o desenvolvimento econômico nacional. Unidade de Ensino de Pós-Graduação, Extensão e Pesquisa, São Paulo, 2011.

LIBÂNEO, J. C. O Ensino da Didática, das Metodologias Específicas e dos Conteúdos Específicos do Ensino Fundamental nos Currículos dos Cursos de Pedagogia. Revista Brasileira de Estudos Pedagógicos, Brasília, v. 91, n. 229, p. 562-583, 2010.

MALDANER, O. A. A Formação Inicial e Continuada de Professores de Química. 2.ed. Ijuí: Ed. Unijuí, 2003.

MARTINS, A. F. P. Ensino de Ciências: Desafios à Formação de Professores. Educação em Questão, Natal-RN, v. 23, n.9, p. 53-65, 2005.

MASETTO, M. T. Competência Pedagógica do Professor Universitário. São Paulo: Summus, 2003.

MIARKA, R.; BICUDO, M. A. V. Forma/ação do professor de matemática e suas concepções de mundo e de conhecimento. Ciência \& Educação, v. 16, n. 3, p. 557-565, 2010.

MORAES, R. Uma tempestade de luz: a compreensão possibilitada pela análise textual discursiva. Revista Ciência \& Educação, Bauru-SP , v. 9, n. 2, p. 191-211, 2003.

MORAES, R.; Galiazi, M. C . Análise textual discursiva. $2^{\circ}$ edição. Editora Unijuí. Universidade Regional do Noroeste do Estado do Rio Grande do Sul. Rio Grande do Sul, 2011.

MORAES, R. Análise textual: discursiva. Ijuí, Editora Unijuí, 2007.

MOREIRA, A. F.; Silva, T. T. Sociologia e teoria crítica do currículo: uma introdução. In A: F. Moreira \& T. T. Silva (Orgs.). Currículo, cultura e sociedade, São Paulo: Cortez, p. 07-37, 1995.

NOGUEIRA, V. O professor no processo educativo: suas histórias e suas ações. Dissertação (Mestrado em Educação) - Universidade Regional de Blumenau, Blumenau, 2003.

OLIVEIRA, L. C. V. As contribuições do estágio supervisionado na formação do docente-gestor para a educação básica. Ensaio - Pesq. Educ. Ciênc. , v. 11, n.2, 2009.

OLIVEIRA, V.S.; SILVA, R.F. Ser bacharel e professor: dilemas na formação de docentes para a educação profissional e ensino superior. Holos, v.2, n.28, p.193-205, 2012. 
OliveIRA, C. B.; GONZAGA, A. M. Professor Pesquisador - Educação Científica: O Estágio como Pesquisa na Formação de Professores para os Anos Iniciais. Ciência \& Educação, v. 18, n. 3, p. 689-702, 2012.

PEREIRA, J. D. E. As licenciaturas e as novas políticas educacionais para a formação docente. Educação \& Sociedade, 1999.

PIETROCOLA, M.; PINHO ALVES, J.; PINHEIRO, T. F. Prática interdisciplinar na formação disciplinar de professores de ciências. In: Investigações em ensino de ciências, vol.8, n.2, 2003. Disponível em: <http://www.if.ufrgs.br/public/ensino/> Acesso em: 20 de Fev. de 2016

PIMENTA, S. G.; LIMA, M. S. L. Estágio e docência. 7. ed. São Paulo: Cortez, 2012.

PINHO, A. M. E. A Contextualização no Ensino de Química ao longo de $\mathbf{1 5}$ anos da Revista Química Nova na Escola. (Mestrado em Educação em Ciências: Química da Vida e Saúde) Universidade Federal do Rio Grande, Rio Grande do Sul, 2014.

QUADROS, A. L. Os professores que tivemos e a formação da nossa identidade como docentes: um encontro com a nossa memória. Revista Ensaio, Belo Horizonte, v. 07, n. 01, p. 04-11, 2005.

QUADROS, A. L. et al. A Formação do Professor Universitário no Percurso de Pós-graduação em Química. Ciência \& Educação, Bauru, v. 18, n. 2, p. 309-321, 2012.

ROSA, J. K. L.; WEIGERT, C.; SOUZA, A. C. G. A. Formação docente: Reflexões sobre o estágio curricular. Ciência \& Educação, v. 18, n. 3, p. 675-688, 2012.

ROSA, M. I. P.; PAVAN, A. C. Discursos Híbridos nas Memórias das Licenciaturas em Ciências em uma Instituição Universitária. Ciência \& Educação, Bauru,v. 17, n. 1, p. 83-96, 2011.

SANGIOGO, F. A et al . Pressupostos epistemológicos que balizam a situação de estudo: algumas implicações ao processo de ensino e à formação docente. Ciências \& Educação, v.19. n.1., p.3554, 2013.

SANGIOGO, F. A. et al. A pesquisa educacional como atividade curricular na formação de licenciandos em Química. Ciência \& Educação, v. 17, n. 3, p. 523-540, 2011.

SILVA, Tomaz Tadeu. Documentos de Identidade: uma introdução às teorias do currículo. 2a ed. Belo Horizonte; Autêntica, 2002.

SOUSA, S. C. T.; LUCENA, J. M.; SEGABINAZ, D. Estágio Supervisionado e Ensino de Língua Portuguesa: Reflexões no Curso de Letras/ Português da UFPB. Raído, Dourados, MS, v. 8, n. 15, 2014.

THIESEN, J. S. A interdisciplinaridade como um movimento articulador no processo ensinoaprendizagem. Revista Brasileira de Educação, v. 13, n. 39, p. 545-598, 2008.

VIVEIRO, A. A.; CAMPOS, L. M. L. Formação Inicial de Professores de Ciências: Reflexões a partir das Abordagens e Estratégias de Ensino e Aprendizagem em um Curso de Licenciatura. Revista de Educação em Ciência e Tecnologia, v.7, n.2, p.221-249, 2014. Disponível em: < https://periodicos.ufsc. br/index.php/alexandria/article/ download/.../2912...> Acesso em: 12 de Jan. de 2016.

WEIGERT, C.; VILLANI, A.; FREITAS, D. Interdisciplinaridade e o trabalho coletivo: análise de um planejamento interdisciplinar. Ciências \& Educação, Bauru, v. 11, n. 1, p. 145-164, 2005. 